\title{
Association of FGD1 polymorphisms with early-onset breast cancer
}

\author{
SARAH BEASLEY ${ }^{1}$, PHILLIP J. BUCKHAULTS ${ }^{2}$, NANCY G. PEDIGO ${ }^{3}$ and CHRISTOPHER L. FARRELL ${ }^{3}$ \\ ${ }^{1}$ Biology Presbyterian College, Clinton, SC 29325; ${ }^{2}$ Drug Discovery and Biomedical Sciences, School of Pharmacy, \\ University of South Carolina, Columbia, SC 29208; ${ }^{3}$ Pharmaceutical and Administrative Sciences, \\ Presbyterian College School of Pharmacy, Clinton, SC 29325, USA
}

Received September 14, 2015; Accepted June 16, 2016

DOI: $10.3892 / \mathrm{ol} .2016 .4911$

\begin{abstract}
Recent cancer studies have suggested that the faciogenital dysplasia 1 (FGD1) gene may play a role in the development of tumor cells. Somatic alterations in the FGD1 gene and increased Fgd1 protein expression have been observed in many breast tumor cases. The present study sequenced the FGD1 gene in tumor DNA from 46 breast cancer patients using Ion Torrent sequencing. Three synonymous polymorphisms and one missense polymorphism were detected with next-generation sequencing; however, no somatic mutations were observed. The Thr697 variant was identified in 18 patients with an average age at diagnosis of 55 years, which was a lower average age than patients without the polymorphism. In addition, a higher frequency of Thr697 was observed in African-American patients. The Pro712 was observed in 15 breast cancer patients with an average age of 58 years, and was observed as a haplotype with the Thr697 variant in $28 \%$ of the breast cancer patients studied. The missense polymorphism (Ala226Thr) was identified in a 40-year-old female patient who had a recurrence of cancer. These polymorphisms (Ala226Thr, Thr697 and Pro712) may be associated with an earlier onset of breast cancer.
\end{abstract}

\section{Introduction}

Breast cancer is one of the most common types of cancer in women, with $>200,000$ new cases annually in the USA (1). Women over the age of 60 years have a greater likelihood of developing cancer; however, for younger females, the development of cancer may be due to inherited genetic variants, also referred to as polymorphisms (2). These polymorphisms have been identified in high-penetrance genes, including

Correspondence to: Dr Christopher L. Farrell, Pharmaceutical and Administrative Sciences, Presbyterian College School of Pharmacy, 307 North Broad Street, Clinton, SC 29325, USA

E-mail: clfarrell@presby.edu

Key words: early-onset breast cancer, faciogenital dysplasia 1 gene, polymorphisms, oncology, next-generation sequencing
ATM serine/threonine kinase, tumor protein P53, and breast cancer 1 and 2, which only account for a small percentage of the breast cancer cases that cause the familial/early onset tumors. Other risks for breast cancer in young females may be due to polymorphisms in genes of moderate/low penetrance.

The faciogenital dysplasia 1 (FGD1) gene encodes for a guanine nucleotide exchange factor (GEF) protein, which is a member of a family of proteins that activate the Rho GTPases (3).Fgd1 protein specifically activates the cell division cycle 42 (Cdc42) GTPase. Cdc42 signals for cellular migration by regulating cytoskeleton restructuring, gene transcription and cell morphology, extension and adhesion. In cancer cells, Cdc42 modulates tumor cell migration and invasiveness $(4,5)$. Researchers have identified that several GEF proteins, such as leukemia-associated Rho-GEF and Rho/Rac GEF 2, have a similar sequence to Fgd1. These GEF proteins are linked to the upregulation of GTPases in tumor cells and have been labeled as potential oncogenes in advanced cancers $(6,7)$.

Recently, researchers have detected overexpression of the Fgd1 protein in infiltrating and poorly differentiated breast and invasive prostate tumors (8). Missense mutations in the FGD1 gene were identified in late-stage tumors of numerous types of cancer tissue, including ovarian cancer, prostate cancer, melanoma, uterine cancer, head and neck cancer $(9,10)$. Amplification at Xp22.2, the FGD1 gene locus, has also been reported in several types of cancer, including breast, uterine, hepatocellular and lung cancers $(9,10)$. Along with somatic alterations, polymorphisms in the FGD1 gene have been linked to an inherited disease and thyroid cancer. Polymorphisms in the FGD1 gene have been associated with a rare $\mathrm{X}$-linked disorder known as faciogenital dysplasia or Aarskog-Scott syndrome (3). This disorder is characterized by short stature and congenital anomalies of the face, skeleton and genitals (11-13). Malformations are consistent with a loss of cellular migration during embryonic development (14). Many of the germline variants are present as either an insertion or a deletion in the FGD1 gene, which results in a frameshift causing inactivation of Fgd1 protein. Several missense changes have also been linked to the disorder. In a recent study, researchers have identified two polymorphisms, rs1126744 and rs12011120, in thyroid cancer (15). However, the status of genetic variants, somatic and germline, in the FGD1 gene has not been studied in breast cancer samples. This 
purpose of the present study was to examine the association of genetic variants in the FGD1 gene with early-onset status using primary breast tumors.

\section{Materials and methods}

Tissue sections and DNA isolation. Frozen tissue sections from breast tumors and corresponding normal breast tissue were obtained through the South Carolina Biorepository System at the Lexington Regional Medical Center (Lexington, SC, USA). The 46 matched-pair samples were de-identified with clinical information for pathological stage and estrogen receptor (ER)/progesterone receptor (PR)/human epidermal growth factor receptor 2 status of the cancer, which is provided in Table I. The frozen tissue sections were prepared for sectioning with Optimal Cutting Temperature Medium (Sakura Finetek, Torrence, CA, USA). The tissue samples were cut into $15-\mu \mathrm{m}$ slices and fixed onto microscope slides using ethanol. The fixed slides were stained with Mayer's hematoxylin (Sigma-Aldrich, St. Louis, MO, USA) and eosin (Harleco; EMD Millipore, Lawrence, KS, USA) to distinguish between tumor and normal cells. Subsequently, tumor and normal cells were extracted from the slides using micro-dissection with an optical microscope. DNA of the micro-dissected cells was isolated using the phenol-chloroform protocol (16). DNA was measured using a Nanodrop spectrophotometer (Thermo Fisher Scientific, Inc., Grand Island, NY, USA). DNA from tumor and normal samples was diluted to a final standard concentration of $10 \mathrm{ng} / \mu \mathrm{l}$. The present study was approved by an Institutional Review Board.

Preparation of polymerase chain reaction (PCR) amplicons for sequencing. The exons of the FGD1 gene and the 'hotspots' for phosphatidylinositol-4,5-bisphosphate 3-kinase, catalytic subunit $\alpha$ (PIK3CA) and AKT1 were identified using the Ensembl website (17). The PCR primers for the exons of the FGD1 gene and hotspots of PIK3CA and v-Akt murine thymoma viral oncogene homolog 1 (AKT1) genes were designed with the PRIMER3 website with a restriction of $300 \mathrm{bps}$ in size (18). P1 and A tag sequences were added to the forward and reverse primers (fusion primer tags) for these genes as described in the Ion Torrent Library Preparation (Fusion Method; Thermo Fisher Scientific, Inc.) (19). PCR of the exons was performed using KAPA HiFi PCR kits (Kapa Biosystems, Wilmington, MA, USA), with a reaction system consisting of $2.5 \mu \mathrm{l}$ of $2 \mu \mathrm{M}$ forward primer, $2.5 \mu \mathrm{l}$ of $2 \mu \mathrm{M}$ reverse primer, $2.4 \mu \mathrm{l}$ of PCR water (Integrated DNA Technologies, Inc., Coralville IA, USA), and $1.5 \mu \mathrm{l}$ of DNA template $(>10 \mathrm{ng})$. Thermal cycling was performed using a 96CFX Thermal Cycler (Bio-Rad Laboratories, Inc., Hercules CA, USA) with the following touchdown protocol: 1 cycle of $95^{\circ} \mathrm{C}$ for $2 \mathrm{~min} ; 3$ cycles of $94^{\circ} \mathrm{C}$ for $10 \mathrm{sec}, 64^{\circ} \mathrm{C}$ for $10 \mathrm{sec}$ and $70^{\circ} \mathrm{C}$ for $30 \mathrm{sec} ; 3 \mathrm{cycles}$ of $94^{\circ} \mathrm{C}$ for $10 \mathrm{sec}, 61^{\circ} \mathrm{C}$ for $10 \mathrm{sec}$ and $70^{\circ} \mathrm{C}$ for $30 \mathrm{sec} ; 3$ cycles of $94^{\circ} \mathrm{C}$ for $10 \mathrm{sec}, 58^{\circ} \mathrm{C}$ for $10 \mathrm{sec}$ and $70^{\circ} \mathrm{C}$ for $30 \mathrm{sec}$; and $50 \mathrm{cycles}$ of $94^{\circ} \mathrm{C}$ for $10 \mathrm{sec}, 57^{\circ} \mathrm{C}$ for $10 \mathrm{sec}$ and $70^{\circ} \mathrm{C}$ for $30 \mathrm{sec}$. The PCR products or amplicons were purified using SPRI Ampure beads (Beckman Coulter Inc., Beverly, MA, USA) following the manufacturers protocol. The purified amplicons were analyzed by electrophoresis on a $3 \%$ agarose gel and photographed using a UVP and BioDoc-it Imaging System (UVP LLC, Upland, CA, USA).

Sequencing with Ion Torrent Personal Genome Machine (PGM) system. The purified amplicons (FGD1, PIK3CA and AKT exons), which consisted of 24 amplicons from each sample, were pooled into two categories. These two amplicon pools were identified as tumor or normal amplicons. The pools of amplicons were sent to the Medical University of South Carolina Proteogenomics Core (Charleston, SC, USA) for evaluation. The amplicons were measured for size using the Agilent Bioanalyzer (Agilent Technologies, Santa Clara, CA, USA). Emulsion PCR of amplicons was performed on the Ion OneTouch 2 instrument, and the amplicons were cleaned and enriched on the OneTouch Enrichment System instrument (Thermo Fisher Scientific, Inc.). The Qubit Fluorometer (Thermo Fisher Scientific, Inc.) was used to determine the amount of amplicons recovered from the enrichment. Sequencing of the tumor and normal samples was performed using two 318 chips on the Ion Torrent PGM instrument (Thermo Fisher Scientific, Inc.).

Variant detection analysis. Data from the Ion Torrent PGM system was analyzed with the CLC Genomics Workbench 6 software (Qiagen CLC Bio, Aarhus, Denmark). The sequencing reads were aligned to the FGD1, PIK3CA and AKT1 reference templates from the National Center for Biotechnology Information (NCBI) (hg19 Build 37) with the Next-Generation Sequencing Tool on the CLC software. Polymorphisms and somatic mutations on the three genes were detected through Probabilistic Variant Detection on the CLC software. Variants that were observed in the tumor and normal reads were confirmed with the NCBI or the 1000 Genomes SNP database websites $(20,21)$. Mutations detected in the tumor sequencing reads were compared to somatic mutations on the cBioPortal and Sanger UK-COSMIC somatic mutation database websites $(9,10)$.

Sanger sequencing of variants. The variants detected in the tumor and normal sequencing reads were identified in the exons of FGD1 and PIK3CA genes. The exons containing variants were amplified using $6.25 \mu \mathrm{l}$ of BioRad EvaGreen Supermix (Bio-Rad Laboratories, Inc.) $2.5 \mu 1$ of $2 \mu \mathrm{M}$ of forward primer, $2.5 \mu \mathrm{l}$ of $2 \mu \mathrm{M}$ reverse primer, $2.4 \mu \mathrm{l}$ of PCR water and $1.5 \mu \mathrm{l}$ of DNA template ( $>5 \mathrm{ng}$ ). Thermal cycling was performed using the 96CFX Thermal Cycler with the following touchdown protocol: 1 cycle of $98^{\circ} \mathrm{C}$ for $2 \mathrm{~min}$; 3 cycles of $98^{\circ} \mathrm{C}$ for $10 \mathrm{sec}, 64^{\circ} \mathrm{C}$ for $10 \mathrm{sec}$ and $70^{\circ} \mathrm{C}$ for $30 \mathrm{sec} ; 3 \mathrm{cycles}$ of $98^{\circ} \mathrm{C}$ for $10 \mathrm{sec}, 61^{\circ} \mathrm{C}$ for $10 \mathrm{sec}$ and $70^{\circ} \mathrm{C}$ for $30 \mathrm{sec} ; 3$ cycles of $94^{\circ} \mathrm{C}$ for $10 \mathrm{sec}, 58^{\circ} \mathrm{C}$ for $10 \mathrm{sec}$ and $70^{\circ} \mathrm{C}$ for $30 \mathrm{sec}$; and $50 \mathrm{cycles}$ of $94^{\circ} \mathrm{C}$ for $10 \mathrm{sec}, 57^{\circ} \mathrm{C}$ for $10 \mathrm{sec}$ and $70^{\circ} \mathrm{C}$ for $30 \mathrm{sec}$. The amplicons were sent to the Beckman Coulter Sequencing Facility (Beverly, MA, USA) for Sanger sequencing, and were sequenced using the $\mathrm{P} 1$ and $\mathrm{A}$ tags from the fusion primers. Sequences were analyzed with the CLC Genomics Workbench.

Statistical analysis. Statistical analysis of genotype frequency, ethnicity and age at diagnosis were performed using the Student's $t$-test in the Social Science Statistics calculator (http://www. 


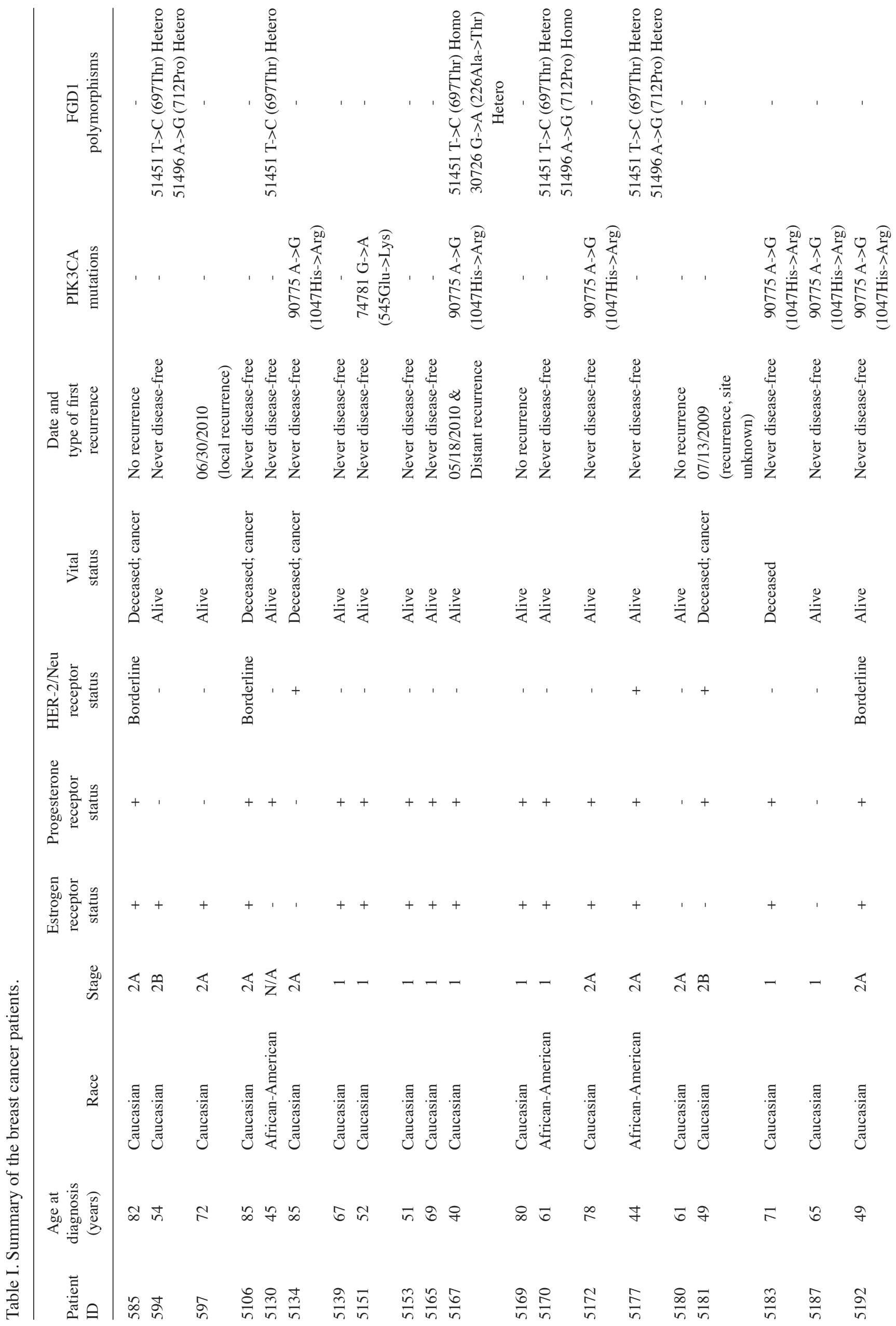




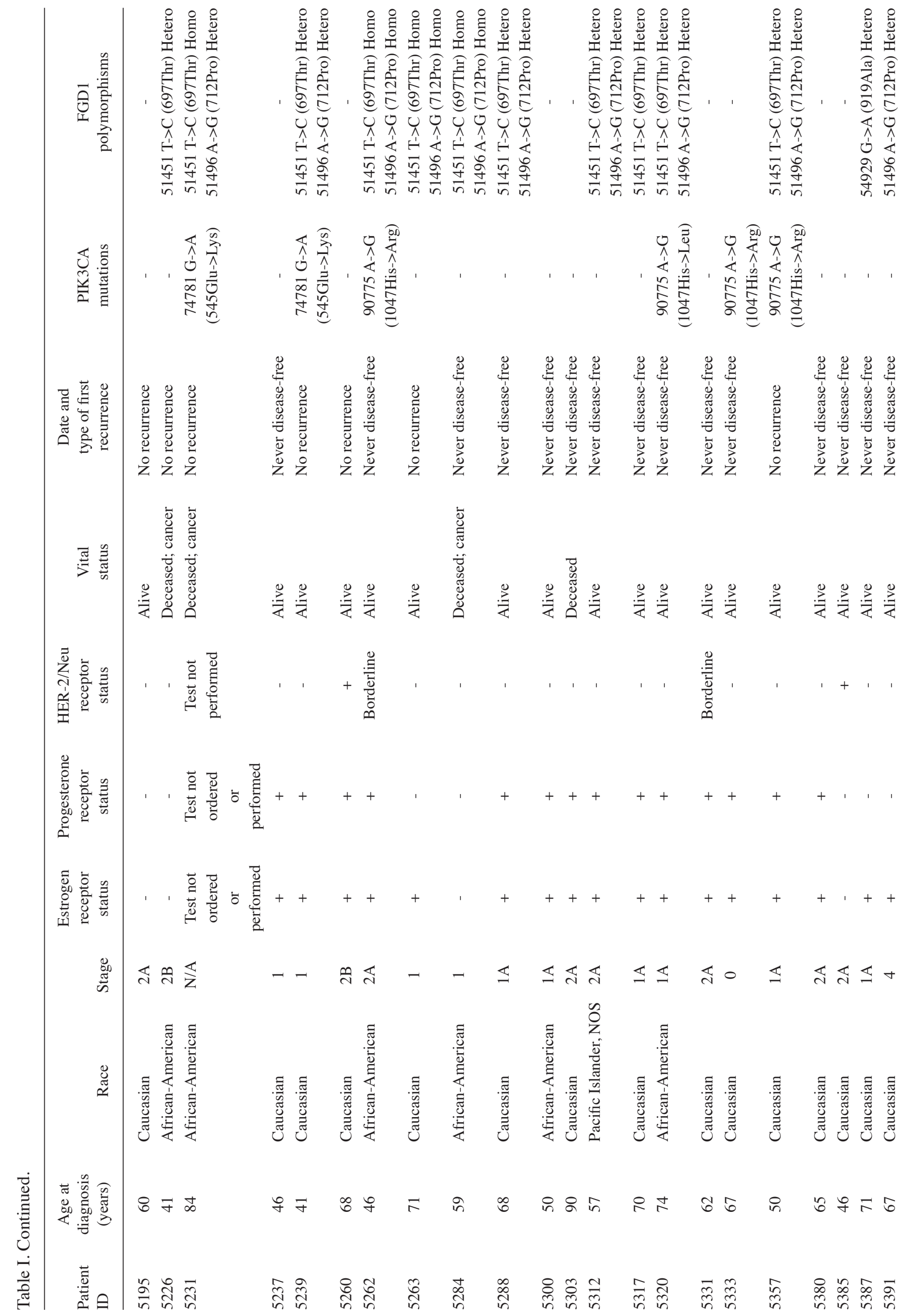


socscistatistics.com/tests/studentttest/Default2.aspx), and Fisher's exact test in GraphPad Prism software (http://www.graphpad. $\mathrm{com} /$ ).

\section{Results}

Somatic variants. The purpose of this sequencing study was to identify somatic mutations and novel polymorphisms of the FGD1 gene in the tissues samples of 46 breast cancer patients. The exons or coding region sequences of the FGD1 gene were sequenced in the tumor and matched normal tissue samples. The 21 primer pairs with Ion Torrent Tags (A and P1) targeted the coding regions of the FGD1 gene, which consists of 18 exons. As positive controls for somatic mutations for next-generation sequencing, exons 10 and 21 of the PIK3CA gene and exon 4 of the AKT1 gene were sequenced in the tumor DNA of the tissue samples. These three exons were selected for the study since positions E542K, E545K, H1047R and H1047L in PIK3CA, and E17K in AKT1 are frequently mutated in tumor DNA sequences of breast cancer patents $(9,10)$. These 24 PCR amplicons were quantitated and equal amounts were pooled together into two groups, tumor and normal, for the next-generation sequencing. The tumor and normal groups of amplicons were bi-directionally sequenced with two runs on the Ion Torrent Sequencer, which produced $3 \times 10^{6}$ individual sequencing reads with an average read length of $250 \mathrm{bps}$

For somatic mutations in PIK3CA and AKT1 for the 46 tumor samples, there were 3 samples with an E545K mutation, 9 samples with a H1047R mutation, and 1 sample with a H1047L mutation. None of the samples had somatic mutations in E542K of the PIK3CA gene or E17K in the AKT1 gene (Table I). These frequencies of PIK3CA mutations were similar to the frequencies that were observed in the cBioPortal and Sanger UK-COSMIC somatic mutation databases $(9,10)$.

Germline variants. The Ion Torrent sequencing of the FGD1 gene resulted with an average depth 170,000 sequencing reads for each of the exons and the reads covered of all 18 exons in the gene. The sequencing of the tumor DNA detected no somatic mutations in any of the 46 tumor DNA samples; however, 3 synonymous variants and 1 missense variant were observed in the tumor and corresponding normal sequencing pools compared with the Ensembl reference sequence of the FGD1 gene (ENSG00000102302; Fig. 1) (17). Two of the variants were detected in the tumor and normal sequencing pools at a frequency of $<1 \%$. The other two variants were identified in exon 14 at frequency of $>20 \%$ in both pools. All of the polymorphisms were confirmed and identified in each of the patient samples using Sanger sequencing (Table I). One of the low-frequency variants from the sequencing study was a $\mathrm{G}$ to A change at position 54446238 in exon 18. This synonymous change (Ala919; rs61734180) was identified in 1 patient who was heterozygous for the polymorphism. The second low-frequency variant was observed in 1 patient who was also heterozygous for the change. The variant was a missense change (Ala226Thr; rs138723423) of an A to a G at position 54470441 in exon 4 . This missense polymorphism was identified in a 40-year-old woman whose tumor was ER/PR positive and it was later discovered that she had recurrence. 


\section{Polymorphisms identified on the FGD1 gene}

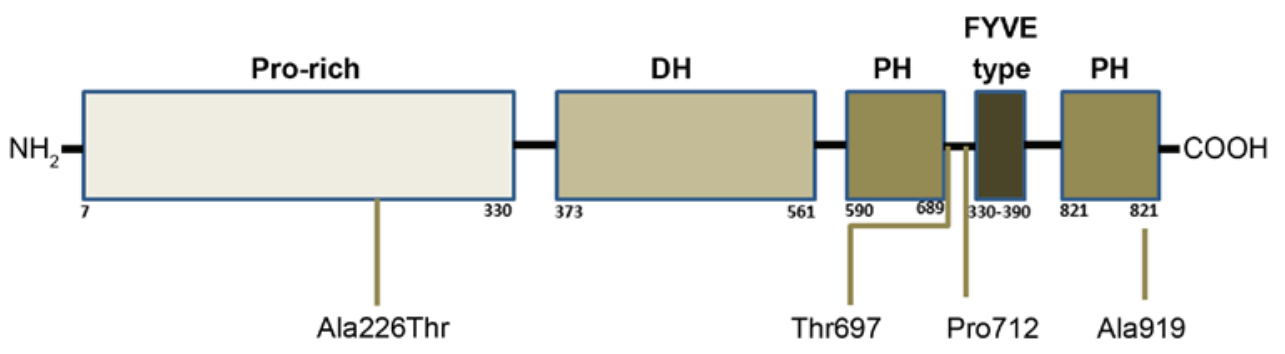

Figure 1. Locations of the FGD1 polymorphisms. Four polymorphisms were identified in the breast cancer patients. FGD1, faciogenital dysplasia 1; DH, Dbl homology domain; PH, Pleckstrin homology domain; Pro-rich, proline-rich with SH3-binding domains.

The silent polymorphism, Thr697 (rs12011120), is found in exon 14 with the change of an A to $\mathrm{G}$ at position 54449671. In this sequencing project, 18 breast cancer patients possessed the Thr697 variant: 10 African-American patients, 7 Caucasian patients and 1 Pacific Islander patient, with an average age at diagnosis of 55 years. Notably, the frequency of this polymorphism was higher among African-American patients $(0.76)$ than in the Caucasian patients $(0.22)$. This difference was statistically significant (two-tailed $\mathrm{P}=0.0018$ ). Although the frequencies between the two ethnic groups differed, the average ages at diagnosis of the African-American and Caucasian patients with the polymorphism were observed to be similar (54 vs. 56 years, respectively). However, the average age at diagnosis of patients without the polymorphism was 10 years older (65 years). A Student's $t$-test was performed to compare the age at diagnosis of patients with the Thr697 polymorphism vs. patients without the polymorphism, and was found to be statistically significant $(\mathrm{P}=0.0175)$.

The second polymorphism, Pro712 (rs1126744), is also found in exon 14 with a $\mathrm{T}$ to $\mathrm{C}$ change at position 54449716 in the FGD1 gene. Pro712 was detected in 15 breast cancer patients (8 African-American patients, 6 Caucasian patients and 1 Pacific Islander patient) with an average age of 58 years. Although the polymorphism was found in a large number of patients, the average age at diagnosis was 58 years, and the age of the Pro712 group was not significantly different when compared with the patients without the polymorphisms $(\mathrm{P}>0.05)$.

Results of the 1000 Genome Project have determined that these two synonymous polymorphisms, Pro712 and Thr697, have a strong linkage of disequilibrium in the general population, with an $r$-value of 0.89 (21). In the current study, these two polymorphisms were observed together in 13 out of 46 breast cancer patients (28\%); this percentage of the two variant haplotypes agrees with the general population percentage of $\sim 31 \%$ (22). The average age at diagnosis of the two polymorphisms together in the breast cancer patients was not significantly different when compared with the patients without the two polymorphisms, based on a Student's $t$-test $(\mathrm{P}>0.05)$.

\section{Discussion}

For several years, FGD1 has been postulated to play a role in diseases involving protein-damaging polymorphisms, as in Aarskog-Scott syndrome, and in the somatic alterations observed in several late-stage/invasive cancer projects $(8-10,12)$. The present study sequenced the FGD1 gene for possible somatic and germline variants that may be associated with tumor development in breast cancer patients. Although somatic alterations have been observed in other studies in late-stage breast cancer $(9,10)$, no somatic FGD1 mutations were identified in the present study. A possible explanation for this difference may be that a majority $(90 \%)$ of the cancer patients in this project were diagnosed with an early stage of breast cancer, with no distant tumor growth or node involvement (stage 1-2). As Fgd1 is associated with late-stage tumor development (8-10), the somatic alterations in the FGD1 gene would not have occurred until the tumor was ready to detach from the primary tumor and migrate through the tissue.

The sequencing of the tumor and normal DNA in 46 breast cancer patients revealed 4 polymorphisms, with 3 silent (Ala919, Thr697 and Pro712) and 1 missense (Ala226Thr) variants. The Ala919 variant was identified in a 70-year-old female patient with an early-stage cancer. This polymorphism is located in the Pleckstrin homology 2 domain and does not appear to play a significant role in tumor development. The two silent variants, Thr697 and Pro712, were observed together in $>20 \%$ of the breast cancer patients; however, they appeared to differ with regard to the age at diagnosis of the patients, with Thr697 being associated with breast cancer in patients who were at least 10 years younger compared with the control (without the polymorphisms), while the age at diagnosis of patients with Pro712 was closer ( $<10$ years) to the control patients. The Thr697 polymorphism also was detected in a higher percentage of African-American patients. Taken together, these results suggest that this polymorphism may play a role in setting the background for subsequent changes that influence early-stage tumor development in breast cancer, and, in particular, may influence early onset in African-American breast cancer patients.

The only missense polymorphism, Ala226Thr, was identified in a 40-year-old female patient with tumor recurrence, which suggests that the variant may be associated with an aggressive form of breast cancer.

In conclusion, although no somatic mutations of FGD1 were observed in the studied population of breast cancer patients, the present results support the hypothesis that the somatic alterations observed in breast cancer may be a late-stage molecular event in tumor development. Three of the 
FGD1 polymorphisms (Ala226Thr, Thr697 and Pro712) that were identified in the breast cancer patients may play role in early onset, or may ultimately influence development of a more invasive form of breast cancer.

\section{References}

1. Siegel R, Naishadham D and Jemal A: Cancer Statistics, 2012. CA Cancer J Clin 62: 10-29, 2012.

2. American Cancer Society: Breast Cancer - Facts \& Figures 2011-2012. American Cancer Society, Inc., Atlanta, GA, 2011. Available at: http://www.cancer.org/acs/groups/content/@ epidemiologysurveilance/documents/document/acspc-030975. pdf.

3. Pasteris NG, Cadle A, Logie LJ, Porteous ME, Schwartz CE, Stevenson RE, Glover TW, Wilroy RS and Gorski JL: Isolation and characterization of the faciogenital dysplasia (Aarskog-Scott syndrome) gene: A putative Rho/Rac guanine nucleotide exchange factor. Cell 79: 669-678, 1994.

4. Yamazaki D, Kurisu S and Takenawa T: Regulation of cancer cell motility through actin reorganization. Cancer Sci 96: 379-386, 2005.

5. Nobes CD and Hall A: Rho, rac, and cdc42 GTPases regulate the assembly of multimolecular focal complexes associated with actin stress fibers, lamellipodia, and filopodia. Cell 81 : 53-62, 1995.

6. Mizuarai S, Kazunori Y and Hidehito K: Mutant p53 induces the GEF-H1 oncogene, a guanine nucleotide exchange factor-H1 for RhoA, resulting in accelerated cell proliferation in tumor cells. Cancer Res 66: 6319-6326, 2006.

7. Kourlas PJ, Strout MP, Becknell B, Veronese ML, Croce CM, Theil KS, Krahe R, Ruutu T, Knuutila S, Bloomfield CD and Caligiuri MA: Identification of a gene at 11q23 encoding a guanine nucleotide exchange factor: Evidence for its fusion with MLL in acute myeloid leukemia. Proc Natl Acad Sci USA 97: 2145-2150, 2000.

8. Ayala I, Giacchetti G, Caldieri G, Attanasio F, Mariggiò S, Tetè S, Polishchuk R, Castronovo V and Buccione R: Faciogenital dysplasia protein Fgd1 regulates invadopodia biogenesis and extracellular matrix degradation and is up-regulated in prostate and breast cancer. Cancer Res 69: 747-752, 2009.

9. Gao J, Aksoy BA, Dogrusoz U, Dresdner G, Gross B, Sumer SO, Sun Y, Jacobsen A, Sinha R, Larsson E, et al: Integrative analysis of complex cancer genomics and clinical profiles using the cBioPortal. Sci Signal 6: pl1, 2013.
10. Forbes SA, Beare D, Gunasekaran P, Leung K, Bindal N, Boutselakis H, Ding M, Bamford S, Cole C, Ward S, et al: COSMIC: Exploring the world's knowledge of somatic mutations in human cancer. Nucleic Acids Res 43 (Database issue): D805-D811, 2015.

11. Orrico A, Galli L, Cavaliere ML, Garavelli L, Fryns JP, Crushell E, Rinaldi MM, Medeira A and Sorrentino V: Phenotypic and molecular characterization of the Aarskog-Scott syndrome: A survey of the clinical variability in light of FGD1 mutation analysis in 46 patients. Eur J Hum Genet 12: 16-23, 2004.

12. Orrico A, Galli L, Faivre L, Clayton-Smith J, Azzarello-Burri SM, Hertz JM, Jacquemont S, Taurisano R, Arroyo Carrera I, Tarantino E, et al: Aarskog-Scott syndrome: Clinical update and report of nine novel mutations of the FGD1 gene. Am J Med Genet A 152A: 313-318, 2010.

13. Aarskog D: A familial syndrome of short stature associated with facial dysplasia and genital anomalies. J Pediatr 77: 856-861, 1970.

14. Schwartz CE, Gillessen-Kaesbach G, May M, Cappa M, Gorski J, Steindl K and Neri G: Two novel mutations confirm FGD1 is responsible for the Aarskog syndrome. Eur J Hum Genet 8: 869-874, 2000.

15. Murugan AK, Yang $C$ and Xing M: Mutational analysis of the GNA11, MMP27, FGD1, TRRAP and GRM3 genes in thyroid cancer. Oncol Lett 6: 437-441, 2013.

16. Sambrook J and Russell DW: Purification of nucleic acids by extraction with phenol: Chloroform. CSH Protoc 2006: pii, 2006.

17. Cunningham F, Amode MR, Barrell D, Beal K, Billis K, Brent S, Carvalho-Silva D, Clapham P, Coates G, Fitzgerald S, et al: Ensembl 2015. Nucleic Acids Res 43 (Database issue): D662-D669, 2015.

18. Untergrasser A, Cutcutache I, Koressaar T, Ye J, Faircloth BC, Remm $M$ and Rozen SG: Primer3 - new capabilities and interfaces. Nucleic Acids Res 40: e115, 2012.

19. Beadling C, Neff TL, Heinrich MC, Rhodes K, Thornton M, Leamon J, Andersen M and Corless CL: Combining highly multiplexed PCR with semiconductor-based sequencing for rapid cancer genotyping. J Mol Diagn 15: 171-176, 2013.

20. Sherry ST, Ward MH, Kholodov M, Baker J, Phan L, Smigielski EM and Sirotkin K: dbSNP: The NCBI database of genetic variation. Nucleic Acids Res 29: 308-311, 2001.

21. 1,000 Genomes Project Consortium, Abecasis GR, Auton A, Brooks LD, DePristo MA, Durbin RM, Handsaker RE, Kang HM, Marth GT and McVean GA: An integrated map of genetic variation from 1,092 human genomes. Nature 491: 56-65, 2012

22. Fu W, O'Connor TD, Jun G, Kang HM, Abecasis G, Leal SM, Gabriel S, Rieder MJ, Altshuler D, Shendure J, et al: Analysis of 6,515 exomes reveals the recent origin of most human protein-coding variants. Nature 493: 216-220, 2013. 